\title{
SOBRE O ESTATUTO DO CONHECIMENTO SOCIOLÓGICO EM BRUNO LATOUR, TIM INGOLD E PIERRE BOURDIEU: UM ESBOÇO COMPARATIVO
}

RESUMO: Este artigo destaca aspectos da recente ênfase em uma "ontologia plana" na teoria antropológica por parte de Bruno Latour e Tim Ingold, procurando-se contrastar essa visão, da qual os dois autores despontam como eminentes representantes, com a perspectiva daquele que frequentemente aparece como "inimigo comum" e que pode ser considerado um dos mais influentes sociólogos contemporâneos: Pierre Bourdieu. O objetivo é tentar expor criticamente um possível debate que, embora ainda pouco explorado no Brasil, tem importantes repercussões na teoria social contemporânea.

Palavras-chave: Teoria social; Teoria antropológica; Virada ontológica.

\section{ON THE STATUS OF SOCIOLOGICAL KNOWLEDGE IN BRUNO LATOUR, TIM INGOLD AND PIERRE BOURDIEU: A COMPARATIVE OUTLINE}

\begin{abstract}
This paper presents some aspects of the recent emphasis on a "flat ontology" in Anthropological theory by Bruno Latour and Tim Ingold, trying to contrast this view, from which the two authors emerge as eminent representatives, with the perspective of that one who often appears as a "common enemy "and who can be considered one of the most influential contemporary sociologist: Pierre Bourdieu. The aim is to try to critically expose a possible debate that, although it is still underexplored in Brazil, has important repercussion in the contemporary social theory.
\end{abstract}

Keywords: Social theory; Anthropological theory; Ontological turn.

\section{INTRODUÇÃO}

No tocante a temas-chave tais como metodologia de pesquisa, ação social e o próprio estatuto do conhecimento científico, ocupam o cerne das discussões na teoria antropológica contemporânea os trabalhos de Bruno Latour e Tim Ingold. As mudanças de visada em relação aos paradigmas dominantes (KUHN, 1978), conforme propostas por esses autores, trazem perspectivas próprias e uma linguagem inovadora para a teoria social. Apesar disso, no Brasil, a recepção dessas reflexões têm se restringido, salvo

\footnotetext{
${ }^{1}$ Doutorando em Ciências Sociais pela Universidade Federal de Juiz de Fora em Ciências Sociais - UFJF. Contato: fabiorarib@gmail.com
} 
notáveis exceções (cf., p. ex., VANDENBERGHE, 2006), ao grupo daqueles envolvidos nas discussões metodológicas e metateóricas travadas no âmbito mais específico da Antropologia local.

O eminente porta-voz da tradição sociológica, problematizada por essa vertente frequentemente denominada "pós-social”, é Durkheim. O fundador da Sociologia como disciplina acadêmica teria, de acordo com certo consenso - que certamente não se restringe a Latour e Ingold (cf., p. ex., LUKES, 1977; GIDDENS, 1998) -, hipostasiado a ideia de sociedade, como corolário do esforço feito para estabelecer uma ciência com um objeto próprio em relação às demais áreas do conhecimento. Ao propor que se tratassem os fatos sociais como coisas, Durkheim estaria afirmando que há uma instância específica, um domínio particular da realidade, com vida própria em relação aos demais, mesmo que fosse com eles relacionado. Um contemporâneo seguidor dessa tradição, referência importante dada sua enorme influência nas ciências sociais, é Pierre Bourdieu. Ao propor que abandonemos a "ontologia do social" em prol do interesse pelas "associações", Latour, por exemplo, confronta certa leitura de Durkheim e do durkheimiano Bourdieu. Este último é ainda apresentado em certos momentos como praticante de uma "sociologia do social" em sua vertente dita "crítica", entendida por Latour como aquela que está ainda mais equivocada, já que postula que os atores, "objetos" de pesquisa, são meros autômatos passivos de estruturas operantes a eles opacas e o pesquisador autoridade que de fato vê o que está por trás, além, acima ou abaixo, podendo e devendo mesmo falar pelos atores (LATOUR, 2012).

Meu objetivo neste trabalho é tentar explicitar esse possível debate em via de mão única (já que não se conhece réplica específica de Bourdieu), debate esse suscitado pelas instigantes contribuições de Latour e Ingold, ambos fornecedores de uma linguagem inegavelmente influente na Antropologia contemporânea. Pretendo fazê-lo de maneira crítica, mas também contrastiva, já que a compreensão reflexiva de um ponto de vista se dá sempre se levando outro(s) em consideração, implícita ou explicitamente. Assim, adoto uma abordagem propositalmente seletiva das contribuições de Latour e de Ingold, norteado pela ênfase naquilo em que elas parecem negar axiomas da sociologia de Bourdieu, cuja teoria mobilizo, com réplica. Em vez de dedicar o tratamento para cada autor em um bloco de texto separado em tópico, como 
normalmente se faz, procurarei manter a exposição contrastiva em todo o corpo do trabalho, no intuito de evidenciar um diálogo possível.

\section{CONTRA AS CLASSIFICAÇÕES}

Latour, de maneira mais explícita, e Ingold, como corolário de suas asserções, esforçam-se para propor uma abordagem diferente daquela que supostamente tem imperado em nossa tradição filosófica ocidental. Essa tradição postularia a existência de um mundo de coisas, essências, que são interpretadas a partir da imposição de categorias de entendimento, residam essas no cérebro humano, em uma predisposição inata, que, no desenvolvimento desse postulado, dado por Lévi-Strauss, seria explicada pela homologia estrutural de todas as coisas do mundo, humanos inclusos (INGOLD, 2001), ou pela origem dessas categorias na organização da sociedade, como formulado por Durkheim e Mauss (DURKHEIM \& MAUSS, 1981). Tanto Bruno Latour como Tim Ingold afirmam que essa perspectiva tem predominado na ciência ocidental e ambos propõem uma ruptura crítica que implica a adoção de outra ontologia como ponto de partida. Em vez de uma estabilidade inicial, imposta por categorias do entendimento ou mesmo correspondentes à própria constituição das coisas, o que temos no mundo é uma infinidade de ações diferenciantes, uma tendência perpétua para a diferenciação que é inerente tanto às ações humanas como às de animais não humanos, já que essa tendência é a "essência" do desenvolvimento da vida no mundo. Possíveis estabilizações nesse fluxo ininterrupto são a exceção, sendo a regra o fluxo, o processo de desenvolvimento, o eterno devir, de modo que relações de causa e efeito entre os fenômenos, por exemplo, só podem ser estabelecidas retrospectivamente, como interpretação simplificadora a posteriori para um conjunto de fenômenos já ocorridos (LATOUR, 2012, p. 65).

Latour entende que não se deve partir do social "tradicional" como modelo (já que este deixa de fora muitas associações importantes e frequentes - como a que se dá com não humanos, por exemplo), mas que se chegue ao social, entendido como toda e qualquer forma de relação, como aquilo que deve ser explicado ao final da pesquisa, tendo como resultado o relato textual de algum conjunto de conexões feitas pelos próprios atores (LATOUR, 2002; 2012). Em vez de seguir uma teoria e buscar sua 
comprovação/exemplificação nos "casos" empíricos, o autor propõe que se comece das próprias incertezas, das controvérsias que povoam o mundo e onde, inclusive, se encontra em maior evidência a atividade de associação (LATOUR, 2012, p. 74), evitando-se substituir as palavras dos próprios atores pelo "léxico do social". Social, para Latour, diferentemente do que postularia a tradição durkheimiana nas ciências sociais, não é uma dimensão específica do mundo a ser sobreposta às demais, mas sim o movimento ininterrupto de ligação ("associação") das coisas no mundo (LATOUR, 2002). Esse movimento produz regularidades sempre parciais, temporárias, instáveis, já potencialmente portadoras de controvérsia. Nas palavras do autor, “(...) definirei o social, não como um domínio especial, uma esfera exclusiva ou um objeto particular, mas apenas como um movimento peculiar de reassociação e reagregação." (LATOUR, 2012, p. 25). À dita "sociologia do social", aquela que parte da sociedade como um âmbito específico, que inclusive teria muitas das vezes proeminência causal sobre outros domínios (como o psicológico ou o biológico, por exemplo), Latour contrapõe uma "sociologia das associações" (LATOUR, 2012, p. 27). Essa não tentaria enquadrar o objeto no modelo de um social suposto a priori, mas buscaria seguir os atores e a rede formada por suas associações. Como formula Latour:

\footnotetext{
'Não vamos tentar disciplinar vocês, enquadrá-los em nossas categorias; deixamos que se atenham a seus próprios mundos e só então pediremos sua explicação sobre o modo como os estabeleceram.' A tarefa de definir e ordenar o social deve ser deixada aos próprios atores, não ao analista (LATOUR, 2012, p. 44).
}

Tal proposição apresenta-se como "simétrica", mais modesta, por assim dizer, já que não se pensa detentora de uma verdade desconhecida dos demais atores e que determinaria o âmbito da realidade a ser observado em virtude dos supostos “mecanismos sociais" ali atuantes. Não se trata de determinar de início a unidade de análise de que partimos, o tipo de mecanismo operante que pressupomos (sejam o habitus, a ideologia, a illusio, a eficácia simbólica...), mas de rastreamos as pistas deixadas pelos atores em suas atividades infinitas de "formação de grupos" (LATOUR, 2012). E os grupos, claro, frutos de atividade incessante - como também insiste Ingold -, estão sempre em movimento, são provisórios, contraditórios, compostos por vozes dissonantes e sempre prestes a se desestabilizar. Aquilo que parece perdurar mais ao 
longo do tempo, a ponto de indicar, aos olhos apressados de um "sociólogo do social", o funcionamento de um mecanismo subjacente, é a exceção, que por isso deve ser explicada, e não a regra nos limites da qual os eventos possam ser enquadrados.

Para esses autores, o problema da lógica cartesiana, dominante na ciência dominante no ocidente, é, para usar formulação de Ingold, a transformação das vias dentro das quais a vida é vivida em limites fixos (INGOLD, 2015). É o que Ingold denomina "lógica da inversão" (INGOLD, 2015). Ao dissertar sobre o deslocamento de seres no mundo, Ingold difere o raciocínio em termos de rede de transporte, que significa a ida de um ponto fixo a outro, como se existissem esses pontos que, enquanto espaços vazios, na condição de forma a ser preenchida por conteúdo, seriam ocupados pelo viajante, de uma abordagem em termos de peregrinação, termo que o autor prefere para descrever a maneira pela qual o movimento de fato se daria. Na peregrinação o espaço é constituído à medida que se avança e só existe no decorrer da trajetória. $\mathrm{O}$ conhecimento se dá no movimento, no processo mesmo de conhecer. O movimento é ele próprio uma maneira de conhecer. Trata-se aqui de uma "compreensão prática do mundo da vida" (INGOLD, 2015, p. 224). Na peregrinação, de acordo com Ingold, importa o próprio trajeto, o movimento em ato. Seu resultado a posteriori, considerando-se as ações simultâneas de muitos agentes, é a composição de linhas que se entrelaçam como em uma malha (INGOLD, 2015, p. 224). Para Ingold, mantendo-se essa imagem geométrica, é na ligação de linhas e não na conexão de pontos que a vida é vivida (INGOLD, 2015, p. 224).

Para evidenciar limites de ontologia dominante na ciência ocidental, o antropólogo britânico a contrasta, por exemplo, com o pensamento predominante em certos povos que vivem na região do Círculo Polar Ártico, entre os quais “(...) as coisas não são classificadas como fatos, ou tabuladas como dados, mas narradas como histórias. E todos os lugares, como um conjunto de coisas, é um nó de histórias". (INGOLD, 2015, p. 227). Esse universo etnográfico estudado por Ingold reforça para ele a constatação de que no mundo não temos substâncias, mas sempre devires. Nada existe em si e por si. As coisas "existentes" são corporificações efêmeras da perpétua “atividade-em-relação-aos-outros" (INGOLD, 2015, p. 247), de modo que o projeto de classificação que alimenta a ciência dominante, ao agrupar e dividir as coisas, atribuindo a elas - ou apreendendo delas - atributos fixos, é mesmo uma impossibilidade 
gnoseológica. Isso porque, repita-se de outra maneira, o conhecimento "é forjado não pelo ajuste dos dados da observação dentro dos compartimentos de uma classificação recebida, mas por meio de histórias de peregrinação." (INGOLD, 2015, p. 229).

Para Bourdieu, em contramão possível dessa argumentação, a prática não é casual; ela não se dá num fluxo ininterrupto no qual há apenas movimento e performance. A ação, na verdade, envolve a aplicação de "esquemas de percepção, de apreciação e de ação que são adquiridos pela prática e colocados em ação no estado prático sem atingir a representação explícita" (BOURDIEU, 2009, p. 157). Esses esquemas "funcionam como operadores práticos por meio dos quais as estruturas objetivas de que são o produto tendem a se reproduzir nas práticas." (BOURDIEU, 2009, p. 157). A lógica da prática, apreensível a partir da ação, apesar de não se restringir à "lógica do erudito" - isto é, ao modelo sociológico elaborado para compreendê-la -, também não se limita à percepção que dela têm os agentes. Sendo assim, seguir o movimento dos agentes é se prender a formulações superficiais e, mais que isso, ocultadoras de uma realidade que cabe à ciência, contrariamente, desvelar. Isso porque, para Bourdieu, uma das funções sociais da prática, sempre embebida nas urgências da vida, é mascarar a realidade das relações, esconder a dominação existente, dissimulando seus princípios. (BOURDIEU, 2009).

Bourdieu defende que a prática é o cerne da ação e põe sua lente na maneira própria de funcionamento dessa razão que se desenvolve no processo. Porém, por não abandonar a ideia de forma, entende que "O corpo está no mundo social, mas o mundo social está no corpo (sob forma de hexis e de eidos).” (BOURDIEU, 2001, p. 185). O "mundo social" é equivalente ao espaço a ser ocupado pelos sujeitos. A forma desse espaço, em grande medida restritiva e gerativa quanto às possibilidades ("estruturada e estruturante", na linguagem do autor) dadas à ação, uma vez que se encontra incorporada como esquemas de percepção, classificação e ação nos próprios sujeitos, constitui e conforma a ação, existe como fruto mais ou menos institucionalizado do acúmulo de recorrências históricas e é em grande parte responsável pelo devir. A ação prática no mundo, portanto, não se dá livremente, ao contrário do que é obrigada a postular uma abordagem processualista, concentrada no fluxo perpétuo. Desenvolve-se com a atualização, em condições sociais dadas, desses esquemas perceptivos e avaliativos que tendem a se constituir ao longo da vida dos indivíduos. Alegar que "o 
mundo social está no corpo", como faz Bourdieu, significa afirmar que as opções dos sujeitos têm grande probabilidade de reproduzir as ocorrências modais esperadas entre os demais sujeitos socializados em um mundo similar. Claro que o ajustamento das disposições subjetivas às condições práticas objetivas nunca é perfeito; constitui um caso particular, mas que é visto por Bourdieu como particularmente frequente nos universos pesquisados por ele (BOURDIEU, 2001, p. 194).

Tim Ingold quer afastar a ação de uma ideia de premeditação. Não há uma forma, "dentro da cabeça", enquanto atributo do ser, que seria imposta ao mundo, de modo que a prática seria o resultado de uma modelação. Para esse autor, a essência da ação está no acoplamento entre movimento corporal e percepção (INGOLD, 2015, p. 151). Bourdieu, como temos visto, também procura enfatizar a dimensão prática da ação, afastando seu caráter pré-reflexivo, aquém da "meditação". Acontece que, inclusive por dispensar a reflexão, a ação reproduz padrões estabilizados no passado, operando em certa medida como reprodução/atualização desses padrões acumulados em circunstâncias sempre presentes. Esses padrões de comportamento, esquemas de percepção e classificação, são inerentes à prática, delimitam possibilidades estatisticamente mais prováveis, de modo que não há apenas fluxo, mas sim, para mantermos a imagem, um fluxo constantemente estabilizado pela atividade dos próprios atores, claro, mas que, uma vez estabilizado, mesmo que temporariamente, passa a ter proeminência sobre as ações futuras. Isso se dá como um processo incessante, sempre em transformação, como Bourdieu não nega ao destacar que o habitus, por exemplo, é fruto de trajetória, isto é, desenvolve-se na história (BOURDIEU, 2001).

O que temos é a constituição de certos esquemas, temporários mas recorrentes, que tendem a domar o perpétuo fluxo da ação. Enquanto em Ingold os "lugares (...) são delineados pelo movimento, e não pelos limites exteriores ao movimento" (INGOLD, 2015, p. 220), para Bourdieu os esquemas de percepção operam de fato como limites ao movimento; limites não porque emanam de uma mente, "limitada pela pele" (INGOLD, 2015, p. 141) e exterior ao mundo, mas porque, enquanto comportamento padronizado através da repetição, tendem a se autonomizar em relação ao próprio fluxo da ação, tornando-se compartilhados por um conjunto de atores que passaram por experiências similares (BOURDIEU, 2001). O que não quer dizer que haja uma substância denominada "sociedade"; não quer dizer que há uma "coisa em si" (postulada pelo 
"kantismo dominante" na fração dominante da ciência ocidental, como formulam igualmente Latour e Ingold), mas que há, para manter a linguagem de Latour, “estabilizações", ou, para utilizar o termo preferido por Ingold, "condensações”. Essas, provisórias, em função do caráter eminentemente econômico ("frugal”) da razão prática (BOURDIEU, 2002; 2009), tendem a se impor como formas de percepção para todos os domínios da prática dos sujeitos.

\section{SEGUIR OS AGENTES, FOCAR O PROCESSO}

Tanto para Latour como para Ingold só há a prática no mundo, sem princípio articulatório subjacente. O conhecimento dos agentes é simétrico ao conhecimento científico; ambos devem ser tomados em igualdade de fato e de direito. Não é que para Latour não haja movimentos recorrentes, relativamente constantes nas ações. Esses elementos existem e por isso podem inclusive ser mapeados (LATOUR, 2002). Acontece que eles estão explícitos nas práticas dos agentes. Para Bourdieu, diferentemente, há princípios subjacentes que comandam a lógica prática e são esses princípios, opacos aos agentes, que devem ser desvelados pelo analista, sujeito que está em posição privilegiada para tal. Segundo o sociólogo francês, trata-se de ir "dos objetos e das condutas aos princípios de sua produção." (BOURDIEU, 2009, p.156). A "teoria explícita da ação" dos agentes corresponde à sua razão prática, que essencialmente não tem consciência de seus princípios geradores. Esses princípios, e nisso Bourdieu se distancia do estruturalismo de Lévi-Strauss (2008), por exemplo, e se filia explicitamente à obra durkheimiana, não devem ser buscados nas categorias universais, sejam do entendimento ou da própria vida (que inclui o entendimento), mas nas estruturas objetivas do mundo social que tornam possíveis os esquemas classificatórios. Cabe ao esforço científico, portanto, “(...) reconstruir o sistema socialmente constituído de estruturas inseparavelmente cognitivas e avaliativas que organiza a percepção do mundo e a ação no mundo em conformidade às estruturas objetivas de um estado determinado do mundo social." (BOURDIEU, 2009, 156).

Uma vez desvelados mecanismos mais frequentes, a análise da prática passa a ser feita no intuito de se buscarem correspondências empíricas com o modelo. Cada ocorrência funciona, portanto, como um “caso particular do possível” (BOURDIEU, 
2009), na formulação de Bachelard que Bourdieu frequentemente usa. Não é o que parece acontecer mais vezes (já que, como se sabe, os paradigmas tendem a ser auto afirmados internamente e funcionarem como delimitadores de grupos de pares no interior da ciência), mas essa abordagem não nega que se possa inclusive encontrar realidades que obriguem a retificação ou mesmo o abandono do modelo em prol de outro mais proveitoso. Entendo, inspirado por Bourdieu, que as ações presentes, a serem rastreadas pelo pesquisador, são em parte moldadas por ações passadas no fluxo da prática. As interações presentes se dão com base em um conjunto de esquemas de ação acumulados ao longo do tempo, tanto pelo indivíduo específico (que, de fato, também corresponde a um grupo, fruto de longo trabalho de construção (LATOUR, 2012, p. 5556)), quanto pelo conjunto de outros que agem simultaneamente. A ênfase no processo (que também pode aparecer relacionada a certa "preguiça analítica"por parte do pesquisador (STRATHERN, 1999)) nega prioridade ontológica às estabilizações da ação, mesmo quanto estas operam como mecanismos acionados pré-conscientemente, ou seja, como razão prática no fluxo da ação.

A visão de um fluxo perpétuo que, em grande medida, se confunde com o próprio senso comum que só enxerga a efemeridade das ações de curto alcance, dá primazia à aparência, conforme captada pelos próprios atores. Por outro lado, essa visão pode atuar como uma permanente advertência ao pesquisador, ainda interessado nos ganhos heurísticos da dita "sociologia do social", sobre o fato de que os modelos não devem se impor à realidade, fazendo desaparecerem os fenômenos (LATOUR, 2012, p. 148), mas como ferramentas que possibilitam o pensamento comunicável, sendo ajustados ou até abandonados em casos de não adequação ao observado.

No caso da Sociologia, entendo que seguir os atores e enfatizar o processo da prática não implica abandonar uma ciência categórica, classificatória ${ }^{2}$, a favor de formas

\footnotetext{
${ }^{2}$ E que, em grande medida, pelo menos na contemporaneidade ocidental, impõe seus padrões de funcionamento para além de suas "fronteiras", já que em grandes medida os próprios atores estão o tempo todo classificando e hierarquizando o mundo nos moldes da razão científica. $\mathrm{O}$ argumento de Bourdieu mostra sua força principalmente quando nos interessamos pelo estudo de realidades mais próximas do pesquisador. Nesses casos lidamos com pessoas que, através de certo movimento que Giddens denomina "reflexividade" (GIDDENS, 1991), compartilham com a ciência predominante uma mesma epistemologia categórica. Os agentes, na vida ordinária, guiada pela razão prática, assim como a ciência, valem-se de categorias para narrar suas trajetórias. Em um mundo em que a especialização funcional financia a dedicação exclusiva de uma casta intelectual, é difícil negar a autoridade de certa ciência hegemônica como visão de mundo dominante, capaz de fazer ver e, portanto, capaz de fazer existir dentro de seus 
narrativas, planas, de eterno devir. É possível manter a prudência epistemológica na constatação de que o mundo não se restringe aos modelos (a lógica das coisas não deve ser confundida com as coisas da lógica) que elaboramos a partir dele sem abandonar o exercício que implica lançar mão de conceitos e confrontá-los com a realidade pesquisada, procurando verificar se eles têm alguma utilidade para uma melhor compreensão de um mundo que de outro modo se apresentaria como imperscrutável caos. Mesmo que, nesse caso, uma vez que todos, pesquisadores e pesquisados, somos agentes no mundo, o que vem a ser a "melhor compreensão" o é provisoriamente, já que está sempre em disputa por milhões de vozes contraditórias, como bem adverte Latour (2002).

$\mathrm{Na}$ vida em conjunto, as estabilizações passam a corresponder à verdade para os agentes. Tornam-se inquestionáveis, em certa medida. Para dizer de outro modo, valendo-me inicialmente da advertência feita por Latour, a existência de controvérsias, correspondente ao "status normal" do mundo, não nega o fato de que elas se deem sobre certos consensos, nem que seja apenas o consenso tácito a respeito das regras do jogo, às vezes compartilhado por aqueles que simplesmente nasceram no jogo. São essas regras de consentimento tácito, indispensáveis para a existência do jogo, que Bourdieu denomina illusio (BOURDIEU, 2001). Um exemplo de acordo elementar está nas regras da própria língua. Sem o compartilhamento desse aparato tecnológico mínimo não há comunicação e, portanto, não há controvérsia possível. A fala, como âmbito da práxis, não se restringe à língua (modelo construído a posteriori, domínio do logos); ela tampouco independe da existência de regras subentendidas pelos agentes. A illusio é o envolvimento prático, pré-consciente, com as regras da língua. A adesão dos agentes, mesmo sem seu consentimento, é o que explica o fato de conseguirem se acertar pelo menos sobre os termos de uma conversa.

Ater-se à prática, sem mais, leva, claro, à sensação de impossibilidade de se destacar regularidades; a não ser que advoguemos em prol da apreensão empirista ingênua do mundo, da aceitação de que há uma correspondência imediata deste em relação ao intelecto, encontrar regularidades (estabilizações) nas práticas dos agentes é encontrá-las em estado implícito, pré-consciente. Partir da teoria, sem desprezar a 
prática, é procurar não elaborar uma teoria para cada circunstância, ou mesmo não evitar qualquer teoria - a partir do receio de estarmos cometendo a falácia da sobre determinação da razão prática pela razão teórica da ciência, esquecendo-se que a lógica da prática é alheia àquela do erudito (BOURDIEU, 2009). Entendo que renunciar à racionalização implica renunciar ao próprio pensamento ou acreditar na possibilidade de relação com o mundo na condição de tabula rasa.

Descrever o mundo, mesmo que se "seguindo os agentes", é inventar um mundo a partir do arcabouço de quem descreve e da inevitável seleção daquilo que lhe pareceu mais relevante nas ações dos agentes (WAGNER, 2010). Como a epistemologia hermenêutica nos adverte, há sempre um nível de interpretação na ação de compreender, independentemente de postularmos ou não a existência de um mundo real, de essências, de "coisas em si", subjacente às diversas interpretações. Quer concebamos que há variações sobre uma base real comum, quer defendamos que só há interpretações, o fato é que seguir os agentes é sempre interpretar o que eles fazem e dizem estar fazendo. Nesse aspecto, não há como escapar da hermenêutica sem adotarmos o realismo ingênuo que ancora seu poder de convencimento na autoridade do senso comum ordinário.

Em Bourdieu, penso, não haveria problema metodológico ou epistemológico em se "seguir os atores" 3 , desde que não nos atenhamos do início ao fim exclusivamente às representações que eles fazem de suas ações, deixando de captar os esquemas que atuam subjacentes às práticas e que inclusive estabelece mas condições de possibilidade delas. Para Bourdieu, o discurso nativo, a porta de acesso aos mecanismos subjacentes, é de fato enganador, pois se encontra fundamentalmente embotado pela prática - e nisso o autor compartilha de entendimento comum a toda uma tradição de pensamento marxista. As representações nativas são "ideologia", correspondem à doxa e tendem a reforçar a eficácia de mecanismos objetivos criados pelas distribuições objetivas dos recursos hierarquizadores do espaço social (capital econômico e cultural, sobretudo), característica por excelência da adesão tácita ao senso comum (BOURDIEU, 2009). Tanto em Latour como em Ingold, por outro lado, discursos (narrativas) são o que

\footnotetext{
${ }^{3}$ É isso que, à sua maneira, o autor propõe e faz em inúmeros momentos. O faz de maneira especialmente destacada na pesquisa que coordena e que culmina no livro A miséria do mundo, publicado originalmente em 1993. 
temos. Se há algum ponto de vista privilegiado, este não é o do observador externo, supostamente capaz de transcender as urgências da práxis, mas o dos atores, que vivem o mundo que nos interessa e traçam suas linhas. Trata-se, portanto, de levar os agentes à sério e verificar o que eles fazem. Em vez de partir das associações prontas na teoria e testar sua correspondência na prática dos agentes, trata-se, nessa instigante voga da Antropologia contemporânea, de partir da prática e verificar as associações que os próprios agentes fazem.

\section{VOZES ASSIMÉTRICAS}

Para Bourdieu, as "normas explícitas do comportamento recobrem os princípios soterrados do sistema" (BOURDIEU, 2009, p. 33). Há princípios subjacentes, mecanismos que operam independentemente do conhecimento dos agentes. $\mathrm{O}$ conhecimento científico, objetivado e consciente da atividade de objetivação, tem nessa atividade o que o diferencia do conhecimento espontâneo da razão prática. $\mathrm{O}$ conhecimento prático dos agentes traz as marcas das urgências da prática e, por isso, é limitado pelo próprio não distanciamento imposto por essas urgências. Há, para Bourdieu, um "princípio gerador das práticas", as quais não se dão livremente ao sabor dos eventos. Esse princípio é estruturado e impõe coerência ao conjunto das práticas de um indivíduo e às ações de diversos atores enquanto coletividade estatisticamente agrupável por similaridades. A abordagem colada à ação, o fato de se "seguir os agentes", de "deixa-los falar", só serve para se captar indícios rastreáveis da operação desses mecanismos tácitos. Ingold e Latour negam a existência desses princípios, frisando o fluxo, o processo, o aspecto aleatório da prática. Para Latour, por exemplo, trata-se de seguir os atores, porque só há ação e ligações formadas como rastros da ação. Não há mecanismos subjacentes em operação. A realidade é plana, por assim dizer. Aquilo que os atores dizem sobre o que fazem e o que realmente fazem importa tanto quanto aquilo que o cientista diz sobre eles, já que ambos os discursos atuam no mesmo plano. Bourdieu, por outro lado, destaca os aspectos de poder, de assimetria, que fazem com que determinados discursos, por emanarem de posições privilegiadas em um espaço hierarquizado, adquiram proeminência estatutária em relação aos demais, seja simplesmente os ofuscando, seja os fazendo ter menor alcance. O destaque às 
assimetrias constitutivas das relações em um mundo que está constantemente sendo hierarquizado seria o contraponto de Bourdieu a uma alegação de Latour como a que segue: "Não é que nós, cientistas sociais, saibamos a resposta oculta por trás dos atores, nem que os 'próprios atores' a conheçam. Na verdade, ninguém tem as respostas - que, por isso mesmo, precisam ser coletivamente encenadas, estabilizadas, revistas." (LATOUR, 2012, p. 202).

De fato, a realidade é construída a partir de múltiplas vozes contraditórias. Nessa atividade "todos os atores fazem alguma coisa e não ficam apenas observando" (LATOUR, 2012, p. 189). Entendo que essa constatação está em perfeita consonância com o esforço antigo e onipresente de Bourdieu para, de acordo com sua formulação, "superar o objetivismo" das abordagens externalistas, que tendem a hipostasiar a existência na sociedade, dando proeminência causal a estruturas que operariam por conta própria, sem mediações e sem a participação dos indivíduos (cf. BOURDIEU, 1968). Para Bourdieu, a realidade é constituída através de "lutas de classificações", isto é, por disputas pela possibilidade "de fazer ver e fazer crer, de dar a conhecer e de fazer reconhecer, de impor a definição legítima (...)" (BOURDIEU, 1989, p. 113). Essa é a questão central: na vida em coletividade algumas das múltiplas vozes são mais audíveis, por assim dizer. Na atividade coletiva de estabilização há atores que são vistos e que se veem como portadores do direito de falar pelos demais, às vezes a despeito dos demais, de modo que o que se torna mais duradouro emana da atividade desses sujeitos e grupos privilegiados. E o privilégio, que opera de acordo com mecanismos tão mais eficazes quanto mais invisíveis (BOURDIEU, 2001), os mantém como autorizadores a priori das representações.

\section{CONCEITOS COMO MODELOS PARA REGULARIDADES}

A negação do modelo como ponto de partida seria a negação do intelectualismo da tradição categórica "do social”. O que teríamos no lugar? Empirismo? Latour não nega que sim. De acordo com ele, sua teoria do ator-rede propõe algo diferente do que no geral faz o pós-modernismo, já que a "multiplicidade é uma propriedade das coisas e não dos seres humanos que interpretam as coisas." (LATOUR, 2012, p. 171). Não se tratam de pontos de vista múltiplos adotados sobre a mesma coisa, mas do fato de que é 
“a própria coisa que se permitiu ser desdobrada como múltipla e, portanto, ser apreendida através de diferentes pontos de vista" (LATOUR, 2012, p. 171). Empirismo sim, mas um "segundo empirismo", diferente da versão humeana da ciência. Um segundo empirismo que "ainda é real e objetivo, mas é mais vivo, mais tagarela, ativo, pluralista, e mais mediatizado" (LATOUR, 2012, p. 169) já que tem por princípio a constatação da existência de múltiplas vozes no mundo e por método a multiplicação de relatos dessas vozes.

Ao se prender à lógica prática da prática, as reflexões de Latour e Ingold colocam em segundo plano a apreensão de regularidades inerentes às ações que investigam. Colocam em segundo plano a elaboração de modelos pelo pesquisador. Mas conceitos, ora, nada mais são que modelos. Conceitos, como veem Deleuze \& Guattari, operam menos como representação do real, mas como operadores (DELEUZE \& GUATTARI, 1992). São ferramentas elaboradas para dar inteligibilidade aos fenômenos. Não são representações, no sentido de correspondentes mentais às coisas, que estariam fora do corpo. Como argumenta Kuhn, tanto as ciências humanas como as naturais baseiam-se em conceitos e estes moldam a percepção. Uma base hermenêutica, interpretativa, fundamenta umas e outras (KUHN, 2006). Conceitos, produtos históricos, são, portanto, formas, categorias de percepção. Entendo que é possível lermos Bourdieu nesse diapasão, concordando com Vandenberghe quando este escreve que o sociólogo francês de fato recorre ao "gesto convencionalista do "como se"" (VANDENBERGHE, 1999, p. 44). É importante destacar que o modo estrutural de verificação adotado por Bourdieu baseia-se não em uma teoria da verdade como correspondência, mas como coerência (VANDENBERGHE, 1999). É certo que o conceito não é simples representação de uma coisa em si "externa ao intelecto", como aponta Ingold (2001). Claro que a razão teórica do erudito enxerga coisas que a razão prática, "frugal" por definição, embotada pelas urgências instantâneas da prática, não vê. No entanto, a razão teórica, mesmo quando crítica e capaz de desvelar muito daquilo que está em estado implícito tanto para si mesma como em estado prático, é uma metáfora sobre metáforas, um discurso sobre discursos - mesmo que se trate de um discurso privilegiado, seja porque é assim socialmente reconhecido (poder simbólico), seja porque os agentes que o praticam dispõe mais que quaisquer outros dos recursos econômicos, de tempo e investimento intelectual acumulado para fazerem o que fazem. 
Penso que nada nos impede de investir na utilização de modelos. Falar em analogia ou homologia, por exemplo, é necessário para compreender e se fazer compreender, como constata Bourdieu (BOURDIEU, 2009, p. 152). Assim como os cientistas propõem estabilizações (conceitos, modelos) para se compreenderem intersubjetivamente, os agentes tomados por interlocutores/objetos de investigação inevitavelmente o fazem ao descreverem suas ações, como necessidade do próprio ato de narrar. No simples ato de se valerem de substantivos para nomearem seres e acontecimentos, por exemplo, lançam mão da referência a propriedades comuns compartilhadas pelo conjunto descrito, lançam mão de categorias, esquemas classificadores que se estabilizaram pelo uso passado, através da experiência, da socialização. Entretanto, em vez de lançarem mão de uma lógica que se propõem consciente de si mesma, não contraditória etc., agem de acordo com os ditames da razão prática, que, como o ethos de honra kabyle, estudado por Bourdieu, "é mais agido que pensado" (BOURDIEU, 2002, p. 33), já que essa razão tem por característica ser feita, por assim dizer, para prescindir de conceitos (BOURDIEU, 2002).

Latour e Ingold, cada um à sua maneira, entendem que a vida é sempre um processo de abertura, não de encerramento em limites fixos, o que os leva a advogar pela primazia epistemológica e ontológica do movimento. Movimento esse que, tanto pelos demais agentes no mundo como por aqueles comprometidos com a atividade especial da pesquisa científica, é apreendido por meio de formas narrativas ao invés de classificatórias. Entendo que é possível nos questionarmos: mas a classificação não é momento inescapável de toda narração? Afinal, as histórias, mesmo que narradas como perpétuo devir, envolvem a nomeação/fixação de coisas, seres, entidades, eventos. O próprio ato de nomear implica o estabelecimento de fronteiras conceituais, "encerramentos", delimitações, mesmo que temporárias.

O raciocínio conceitual é eminentemente reducionista. Nas ciências sociais, partir do modelo, mesmo que para abandoná-lo no contato com o empírico, é adotar a advertência weberiana, concluindo que isso é tudo o que temos (WEBER, 2001). A redução da multiplicidade do real é recurso heurístico que, ciente da artificialidade inevitável do procedimento, simplifica para conseguir pensar, limita para poder compreender, especifica para conseguir comunicar. Nesse sentido, apontar poucas ou uma causa para fenômenos complexos não denuncia a má qualidade da análise, mas é a 
própria condição de possibilidade da análise. O que não quer dizer, claro, que a complexidade do mundo caiba no modelo. Não é disso que se trata. Penso que é possível recebermos as reflexões de Latour e Ingold como advertências para que nunca nos satisfaçamos com o fechamento dos relatos nos limites de um texto, muito menos que acreditemos que a complexidade está eliminada a partir do momento em que, como um deus ex machina, introduzimos o modelo teórico para dar conta de todo o observado. Multiplicar as agências consideradas no relato não impõe que abandonemos os modelos.

\footnotetext{
Desdobrar significa simplesmente que, no relato conclusivo da pesquisa, o número de atores precisa ser aumentado; o leque de agências que levam os atores a agir, expandido; a quantidade de objetos empenhados em estabilizar grupos e agências, multiplicada; e as controvérsias em torno de questões de interesse, mapeadas (LATOUR, 2012, p. 201).
}

Como também é possível verificar, entretanto, nem tudo são de semelhanças entre os autores contrastados até aqui. As críticas de Bourdieu e Ingold ao estruturalismo, por exemplo, aproximam-se, no sentido de que ambos apontam o erro em que consiste a imposição pelo pesquisador da lógica erudita à lógica prática, supondo-se que esta última opera nos mesmos moldes da primeira. Para Bourdieu, entretanto, a diferença entre as lógicas é de alcance e de método. Tanto que para superar o obstáculo inercial e romper com o raciocínio espontâneo da doxa, seja ela a erudita, seja a do senso comum ordinário, é necessário, de acordo com o autor, a eterna "vigilância epistemológica", isto é, o esforço consciente para se afastar as praenotiones (como já em Descartes, afinal), em nome de uma ciência rigorosa. Já para Ingold o problema é de natureza epistemológica: o conhecimento, mesmo o científico, "erudito", se dá na prática e não como a aplicação de esquemas mais ou menos ordenadores a um mundo existente. Acontece que em Bourdieu os conceitos são ferramentas; a lógica científica, que perscruta o mundo destacando regularidades e que permite a observação e a própria narração com sentido intersubjetivamente compreensível, não se confunde com a lógica da prática, sendo apenas um modelo construído a fim de compreendê-la (BOURDIEU, 2009).

Nessa discussão, é possível compreendermos que ao final o que temos como material de pesquisa são narrativas; elas dão um acesso aos sentidos da ação, nosso 
objeto de investigação. Resta decidir se desconfiamos delas, como o faz Bourdieu (postulando que escondem e refletem estruturas subjacentes mais reais) e se assim as tomamos apenas como fonte de pistas para o desvelamento de mecanismos, ou se as seguimos, como propõem, cada um à sua maneira, Latour e Ingold, reportando-as no texto como versões provisoriamente congeladas no tempo daquilo que os agentes relatam no fluxo perpétuo da ação. Do mesmo modo que Latour, penso que "razões científicas, políticas e mesmo morais" (LATOUR, 2012, p. 69) determinam a escolha sobre se "convém que os pesquisadores definam antes dos atores, e no lugar deles, o elemento básico de que o mundo social é feito.” (LATOUR, 2012, p. 69).

O cerne de meu esforço neste texto consistiu em tentar explicitar, da maneira mais parcimoniosa que consegui, em que medida as razões de Latour e Ingold podem operar, mesmo que aquém de suas pretensões, como advertências contra os excessos de uma relação reificadora com a "sociedade" - o "como se" necessário para o funcionamento da Sociologia como eu a vejo - e autoritária com os agentes, riscos os quais, mesmo que conscientes por parte de Bourdieu, estão contidos no cerne de sua teoria e erros sobos quais ela pode sucumbirem momentos de aplicação prática mais mecânica aos objetos de pesquisa.

\section{BIBLIOGRAFIA}

BOURDIEU, P. Structuralism and theory of sociological knowledge. Social Research, V. 35, N. 4, p. $681-706,1968$.

O poder simbólico. Lisboa: Difel, 1989.

A casa kabyle ou o mundo às avessas. Cadernos de Campo, São Paulo, V. 8, N. 8, p. $147-159,1999$.

Meditações pascalianas. Rio de Janeiro: Bertrand Brasil, 2001.

O senso de honra. In: Esboço de uma teoria da prática, precedido de três estudos de etnologia Cabila. Oeiras: Celta Editora, 2002.

O senso prático. Petrópolis, RJ: Vozes, 2009.

DELEUZE, G. \& GUATTARI, F. O que é um conceito? In: O que é Filosofia? Rio de Janeiro: Editora 34, p. 25 - 47, 1992. 
DURKHEIM, É.; MAUSS, M. Algumas formas primitivas de classificação. In: MAUSS, Marcel. Ensaios de sociologia. São Paulo, Perspectiva, p. 399 - 455, 1981.

KUHN, T. As revoluções como mudanças de concepção de mundo. In: A estrutura das revoluções cientificas. São Paulo: Perspectiva, p. 145 - 171, 1978.

O caminho desde a estrutura. São Paulo: Editora UNESP, 2006.

GIDDENS, A. As consequências da modernidade. São Paulo: Editora UNESP, 1991.

Durkheim e a questão do individualismo. In: Política, sociologia e teoria social. São Paulo: Editora UNESP, p. 147 - 168, 1998.

INGOLD, T. From complementary to obviation: on dissolving the boundaries between social and biological anthropology, archaeology and psychology. Zeitschrift fur Ethnologie, N. 123, V. 1, p. 21 - 52, 1998.

Culture, nature, environment: steps to an ecology of life. In: The Perception of the environment: essays of livelihood, dwelling and skill. New York: Routledge, 2001, p. $13-26,2001$.

Vozes, 2015.

Estar vivo: ensaios sobre movimento, conhecimento e descrição. Petrópolis:

LATOUR, B. Gabriel Tarde and the End of the Social. In: JOYCE, P. (ed. by). The social in question: new bearings in history and the social sciences. Routledge: London, p.117 - 132, 2002.

Reagregando o social: uma introdução à teoria do Ator-Rede. Salvador: EDUFBA-EDUSC, 2012.

LÉVI-STRAUSS, C. Análise estrutural em linguística e antropologia. In: Antropologia estrutural I. São Paulo: Cosac Naify, p. 43 - 66, 2008.

LUKES, S. Bases para a interpretação de Durkheim. In: COHN, Gabriel (Org.). Sociologia: para ler os clássicos. Rio de Janeiro: Livros Técnicos e Científicos, p. 15 46, 1977.

STRATHERN, M. No limite de uma certa linguagem. Mana, Rio de Janeiro, N. 5, V. 2, p. 157 - 175. (Entrevista concedida a Eduardo Viveiros de Castro e Carlos Fausto) 1999.

VANDENBERGHE, F. The real is relational: an epistemological analysis of Pierre Bourdieu's generative structuralism. Sociological Theory, N. 17, V. 1, p. 32-67, 1999. 
Construção e crítica na nova sociologia francesa. Sociedade e Estado, Brasília, v. 21, n. 2, p. 315 - 366, maio/ago., 2006.

WAGNER, R. A Invenção da cultura. São Paulo: Cosac Naify, 2010.

WEBER, M. Metodologia das ciências sociais. Parte 1, $4^{\mathrm{a}}$ Ed. São Paulo: Cortez, 2001. 